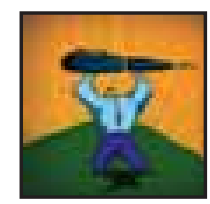

Quarterly Letters

\title{
Some Thoughts on Public and Private Places in Canadian Healthcare
}

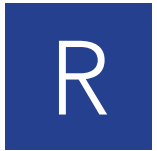

aisa Deber's article "Public and Private Places in Canadian Healthcare" (Hospital Quarterly, vol. 1 no. 2, Winter 1997/98) has a great deal of appeal to those who are of the view that all we need to fix our healthcare system is more government resources. With respect, I believe that this is no longer a tenable proposition. Advances across the broad spectrum of healthcare from pharmaceuticals to surgical procedures, coupled with the increased healthcare demands and expectations of consumers, make it virtually impossible for government alone to maintain the level of care which Canadians have come to expect.

The Canadian expectation or, as Prof. Deber describes it, Medicare's contract with the Canadian public, is primarily and fundamentally for free and equal access for all Canadians to basic health services. However, even under our current regime this does not include all health services, and the public has come to accept that certain services are not without a cost, either in terms of delayed treatment or expense or both. Our government's spending on healthcare is one of the highest in the world, yet the definition and extent of insured health services seems to be eroding.

In the face of the many challenges to our healthcare system, the role of government as a provider of services must be examined. Canadians are entitled to question whether the government should have the exclusive right to provide those services and at what cost. Perhaps then we can better understand the role which the private sector can and ought to play in this matter. For instance, if we accept that government spending on healthcare should not increase significantly over the next decade or more (either as a percentage of GDP or as an added tax burden on Canadians), then, as many learned authors have suggested, we must insist upon better value through the restructuring and re-engineering of healthcare delivery. But if, as I suspect, all the reengineering under the sun will not provide new sources of capital or significant increases in funding, then we must be prepared to look at alternative structures and sources of funding if we are to maintain our high quality of healthcare.

With the greatest respect to Prof. Deber, the problem with healthcare is not simply one of allocation of funds. Too much money has already been taken out of the system or will be required in the future in order to keep pace with medical and technological demands. While I am willing to devote a significant amount of my earnings and time to the health of the population of Canada, I have difficulty entertaining the notion that my taxes should consistently rise to meet this requirement. I believe the public accepts that our system of healthcare is worth protecting, but not without an accounting for its cost and some sensible ways of measuring results as well as allocating our resources.

The fears which Prof. Deber expresses about the private sector are, in my view, exaggerated and unjustified. Unfortunately for its critics, no system has yet to be found that can rival freemarket enterprise for creating innovative products and services at competitive prices while maintaining cost efficiency and quality assurances. The role of government in overseeing quality and service should be to encourage competition which leads to innovation.

In my role as a hospital trustee for the past five years, I have witnessed miraculous achievements by people devoted to their calling, whether it is in nursing, administration, medicine or community care. Few, if any, of these achievements had anything to do with the "bottom line," or profit motive. The real challenge for us all is to find new ways of partnering with our communities - corporate and otherwise - to rejuvenate our healthcare system, while preserving its values and encouraging the miracle workers within it. IE

\section{Rod Wilkinson is a partner with the law firm of Bennet Jones Verchere and Co-Chair of Etobicoke General Hospital in Toronto.}

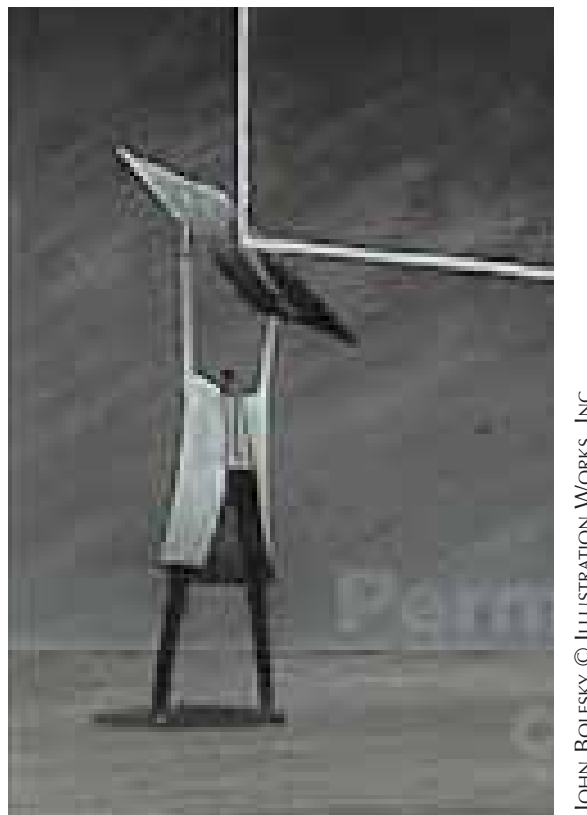




\section{... and the Minister Comments}

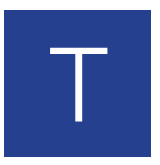

he federal government's approach to health care, and to the health of Canadians, begins with such core values as compassion, equity and collective responsibility. These values underlie the concept of Medicare: a single-payer, publicly funded health care system that provides access to high-quality, medically necessary health services for all Canadians, based on medical need and not on personal wealth.

The concept of Medicare begins with the premise that partnerships are the key to sustaining, improving and modernizing our health care system. For example, Health Canada and one of its partners, the Canadian Institute for Health Information, have identified health care leaders' key health information priorities through the National Health Needs Assessment. The establishment of standards, which is a first step toward the establishment of national benchmarks, was identified as a priority.

The Federal/Provincial/Territorial Advisory Committee on Health Services provides policy advice to the Conference of Deputy Ministers on the utilization, appropriateness, quality, effectiveness and affordability of health services and related investments in our capacity to deliver them. Health care is in a period of rapid transition, and this has resulted in the development of many new issues and stresses. Changes are occurring because of many factors, including advancements in knowledge, better drugs and less invasive surgeries. These advancements have, in turn, resulted in shorter hospital stays, more treatment being performed on an out-patient basis and hospital closings. The fiscal pressures faced by governments and their need to end the cycle of deficits program in Ontario. manage the program. have also contributed to the pace of change and the increased stresses on the health care system.

In the recent Speech from the Throne, we made a commitment to respond to the expanding need for home care, community care, better access to medically necessary drugs and improvements in Canadian health information systems. These issues have been identified by the National Forum on Health, in consultation with Canadians, as priorities for strengthening and modernizing our healthcare system. Making progress in these areas will allow us to take advantage of new developments in technology and research, address the needs of an aging population and constrain the demand for hospital beds.

By working with the provinces and territories, and by helping to build a consensus, the Government is confident that it can help to reshape our health care system in ways that will address the needs of Canadians in the new millennium. The Government, and I as Minister of Health, have made it clear that the new resources that are needed will be provided on a sustained and sustainable basis. IE

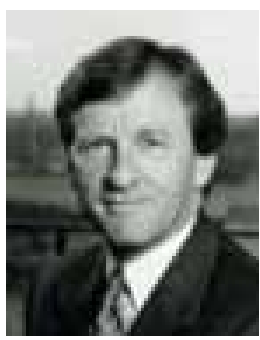

Allan Rock is Minister of Health

\section{Significant Leadership Opportunity in Aboriginal Wellness}

An opportunity exists to prepare a national wellness program for a major Canadian Aboriginal group. This is a six-months contract position. A national strategy is to be developed plus a regional pilot

Interested individuals should have extensive experience in aboriginal health, public health and government relations and a full appreciation for the developing integration of healthcare in Canada. This contract may result in a permanent position to

Letters of interest should provide education, experience and employment or project history. Please post your letter to: Hospital Quarterly - 260 Adelaide St. East, Box 8, Toronto, Ontario M5A 1 N1. (no phone calls please, this service is provided on behalf of a client) 